\title{
Reduced male fertility in childhood cancer survivors
}

\author{
Sun Hee Lee, MD', \\ Choong Ho Shin, MD, PhD ${ }^{2}$
}

'Department of Pediatrics, Gachon University Gil Medical Center, Incheon, ${ }^{2}$ Department of Pediatrics, Seoul National University College of Medicine, Seoul, Korea
Received: 23 December, 2013

Accepted: 24 December, 2013

Address for correspondence: Choong Ho Shin, MD, PhD Department of Pediatrics, Seoul National University Children's Hospital, Seoul National University College of Medicine, 101 Daehak-ro, Jongno-gu, Seoul 110-744, Korea

Tel: +82-2-2072-3570

Fax: +82-2-743-3455

E-mail:chshinpd@snu.ac.kr
With advances in cancer treatment, more pediatric cancer patients have increased their life expectancy. Because cancer-related therapy causes various physical and psychological problems, many male survivors experience later problems with thyroid and sexual functions, and with growth. As outcomes have improved, more survivors need to maintain their reproductive function to maximize their long-term quality of life. Cancer and cancer-related treatment can impair fertility by damage to the testes, to the hypothalamic-pituitary-gonadal axis, or to the genitourinary organs. Prior radiation therapy to the testes, the use of alkylating agents, and central hypogonadism further impair fertility in male survivors of childhood cancer. Following any course of chemotherapy, peripubertal maturation, any testicular volume changes, and symptoms of androgen deficiency should be monitored systematically. If patients request fertility testing, spermatogenesis status can be evaluated either directly by semen analysis or indirectly by determination of the levels of testosterone/gonadotropins and by monitoring any changes in testicular volume. According to the patient's condition, semen cryopreservation, hormonal therapy, or assisted reproduction technologies should be provided.

Keywords: Infertility, Chemotherapy, Radiotherapy, Male, Survivor

\section{Introduction}

According to the nationwide statistics of the National Cancer Center, the 5-year event-free survival rate of Korean boys and adolescents with cancer between 2001 and 2005 was about $70 \%{ }^{1)}$. Two out of three survivors experienced later effects and $43 \%$ had delayed endocrine effects, including thyroid (22\%), sexual (22\%), growth (17\%), and metabolic (6\%) dysfunctions ${ }^{2)}$. As outcomes have improved, more survivors need to maintain their reproductive function to maximize long-term quality of life ${ }^{3)}$.

Spermatogenesis depends on the proliferation and maturation of germ cells derived from spermatogonial stem cells in the seminiferous tubules, which comprise both germinal and Sertoli cells. Spermatogenesis is regulated through endocrine interactions between the hypothalamic-pituitary axis and Sertoli cells. Follicle stimulating hormone (FSH) stimulates the Sertoli cells to secrete androgen-binding protein, facilitating germ cell differentiation by binding to testosterone.

Cancer and cancer-related treatments can impair male fertility by damage to the testes, to the hypothalamic-pituitary-gonadal axis, or to the genitourinary organs ${ }^{4,5}$. Recognizing treatment-associated reproductive risks and educating survivors and providers are very important for improving the health and quality of life of male survivors of childhood cancer. This article reviews the late effects of pediatric cancer therapies on fertility and fertility preservation options.

\section{Risk factors}

Reduced fertility is common among adult survivors of cancer who received some form of 
chemotherapeutic agents, testicular radiation, or experienced damage to the hypothalamus or pituitary glands. In 2009, the Childhood Cancer Survivor Study (CCSS) reported that radiation therapy to the testes of more than $7.5 \mathrm{~Gy}$, a cumulative alkylating agent dose score of $\geq 2$, treatment with procarbazine, or treatment with high doses of cyclophosphamide were the major factors decreasing the likelihood of a cancer survivor achieving a pregnancy, as measured by the hazard ratio $(\mathrm{HR})^{6}$.

\section{Chemotherapy-induced gonadal failure}

If chemotherapeutic agents do not kill stem spermatogonia, spermatogenesis recovers within 12 weeks after the cessation of therapy ${ }^{7,8)}$. However radiation or chemotherapy drugs (e.g., alkylating agents) that kill stem cells can induce azoospermia that lasts much longer than 12 weeks $^{5}$. Spermatogenesis can be impaired by agents that alkylate DNA (e.g., cyclophosphamide, mechlorethamine, ifosfamide, procarbazine, busulfan, melphalan, and the nitrosoureas BCNU [carmustine] and CCNU [lomustine]) that cross-link DNA (e.g., cisplatin). The CCSS reported that survivors aged 15-44 years who were not surgically sterile were less likely to sire a pregnancy than siblings. For example, treatment with cyclophosphamide (parenteral $>9.2 \mathrm{~g} / \mathrm{m}^{2}$, oral $>10.637 \mathrm{~g} / \mathrm{m}^{2}$ ) produced HR of 0.42 with a $95 \%$ confidence interval (CI) of -0.31 to 0.57 ; procarbazine treatment $\left(4.2-7.0 \mathrm{~g} / \mathrm{m}^{2}\right)$ produced HR of 0.48 with $95 \% \mathrm{CI}$ of -0.26 to $0.87^{6}$.

The cumulative dose of a cytotoxic agent determines the duration and magnitude of impaired spermatogenesis. Prolonged azoospermia is associated with the total cumulative dose of cyclophosphamide (single agent ${ }^{9)}, \geq 19 \mathrm{~g} / \mathrm{m}^{2}$; combination with other drugs $\left.{ }^{10)},>7.5 \mathrm{~g} / \mathrm{m}^{2}\right)$, procarbazine ${ }^{11)}$ $\left(\geq 4 \mathrm{~g} / \mathrm{m}^{2}\right)$, melphalan ${ }^{12)}\left(\geq 140 \mathrm{mg} / \mathrm{m}^{2}\right)$, cisplatin ${ }^{13)}(\geq 500 \mathrm{mg} /$ $\left.\mathrm{m}^{2}\right)$, busulfan ${ }^{14)}\left(\geq 600 \mathrm{mg} / \mathrm{m}^{2}\right)$, and chlorambucil ${ }^{15)}(\geq 1.4 \mathrm{~g} /$ $\mathrm{m}^{2}$ ). In addition, treatments with adriamycin, vinblastin, or cytosine arabinoside have additive effects with the above agents in causing prolonged azoospermia, but cause only temporary reductions in sperm count when not so combined ${ }^{5)}$. Whether the prepubertal testis is less sensitive than the postpubertal testis to damage by chemotherapy is not known. The CCSS reported that only very young boys ( $<4$ years of age at diagnosis) were more likely to sire a pregnancy later in life than those who were $15-20$ years of age at diagnosis ${ }^{6}$. Although the prepubertal testis does not show complete spermatogenesis, there is evidence that cytotoxic treatment given to prepubertal boys affects their later fertility ${ }^{10,16)}$. The Children's Oncology Group suggests that having a prepubertal status at diagnosis is not protective against germ cell toxicity of alkylating agents ${ }^{17)}$.

\section{Radiation-induced gonadal failure}

Testicular germ cells are very sensitive to radiation and germinal cell depletion is dose dependent. Thus, a direct radiation dose as low as $0.15 \mathrm{~Gy}$ can cause a significant depression in the sperm count and temporary azoospermia can occur after a dose of $0.3 \mathrm{~Gy}^{18,19)}$. Higher doses cause a more rapid onset of oligospermia and azoospermia by a direct effect on the later stages as well as earlier stages of spermatogenesis ${ }^{19)}$. Differentiating cells are damaged by doses as low as $1 \mathrm{~Gy}$, which reduce the numbers of spermatogonia and preleptotene spermatocytes ${ }^{18)}$. Irradiation with much higher doses (2-3 Gy) kills spermatocytes with a resultant decrease in spermatid numbers. Spermatids show no overt damage, but after 4-6 Gy irradiation the resultant spermatozoa are significantly decreased in number, signifying that some spermatid damage must have occurred ${ }^{19)}$. During the first 50-60 days after lowdose irradiation (1.5-2 Gy), sperm production remains above $50 \%$ of control values and then drops dramatically with resultant temporary oligo/azoospermia ${ }^{19)}$. A single testicular dose of radiation exceeding 4-6 Gy can result in permanent azoospermia ${ }^{16,18,20)}$. Fractionated irradiation of the testes can be more harmful; thus, fractionated doses greater than 0.35 Gy cause aspermia with the time taken for recovery increasing with dose, and with doses of more than $2 \mathrm{~Gy}$, aspermia may be permanent ${ }^{21)}$.

\section{Comparison between post- and prepubertal males}

By appropriately expressing chemotherapy doses on a per meter squared basis and calculating radiation doses to the gonad, the doses of a variety of chemotherapy and radiotherapy regimens that can produce permanent azoospermia in survivors of childhood and adolescent cancers after they reach puberty appear to be the same as those for adults ${ }^{22}$. Radiosensitivity is much lower in Leydig cells than in spermatogenic cells. Radiosensitivity is higher in prepubertal boys than adult men, so the testicular irradiation dose inducing Leydig cell dysfunction is $>20$ Gy in prepubertal subjects [2493061] and this dose is known to be higher after puberty ${ }^{23)}$. The CCSS showed that the likelihood of survivors siring a pregnancy decreased after radiation administered to the testes exceeded $7.5 \mathrm{~Gy}$ (HR, 0.12; $95 \% \mathrm{CI},-0.02$ to 0.64$)^{6}$.

\section{Radiation-induced gonadotropin deficiency}

Gonadotropin deficiency can develop when the hypothalamus and pituitary gland are damaged by surgery, tumors, or cranial radiation. Because radiation-induced gonadotropin deficiency is dependent on irradiation dose and target tumor location, conventional fractionated cranial irradiation (30-50 Gy) induces gonadotropin deficiency in $60 \%$ of pituitary tumor survivors after 10 years and in $>20 \%$ of patients with nonpituitary brain tumors ${ }^{4)}$. The severity of gonadotropin deficiency varies from subclinical to severe, when it can diminish the levels of circulating sex hormones. Radiationinduced gonadotropin deficiency also has a wide clinical spectrum from subclinical to severe forms. Clinically significant gonadotropin deficiency is usually a late complication with 
a cumulative incidence of $20-50 \%$ on long-term follow-up, regardless of whether radiation was administered in childhood or during adulthood ${ }^{4)}$.

\section{Assessment}

Assessment of male reproductive function starts from the assessment of pubertal development. For survivors exposed to alkylating agents (higher cumulative doses or combinations of alkylators) or radiation ( $\geq 20 \mathrm{~Gy}$ to the testes and pelvis; $\geq$ 30 Gy to the cranium) before the onset of puberty, the Children's Oncology Group Long-Term Follow-Up Guidelines for Survivors of Childhood, Adolescent, and Young Adult Cancer (COG-LTFU Guidelines) recommend annual assessment of pubertal development until sexual maturity using Tanner staging, with testicular volume determined using a Prader orchidometer ${ }^{17}$. If patients request fertility testing, spermatogenesis status is evaluated either directly by semen analysis or indirectly by determination of the levels of gonadotropins and testicular volume changes. Men with an abnormal semen analysis should be counseled that it is nearly impossible to predict whether or not an individual's testicular function will recover after treatment, or over what period of time the recovery will or will not occur. Therefore, contraception should be used if paternity is not desired ${ }^{177}$.

\section{Semen analysis}

Semen analysis is the initial investigation of fertility potential in cancer survivors. This test provides information about the functional status of the germinal epithelium, epididymis, and accessory sex glands. The World Health Organization (WHO) manual has established new reference values for semen characteristics in its 5th edition, which are lower than those reported previously ${ }^{24,25)}$. Although semen analysis provides useful descriptive data including sperm count, motility, vitality, and morphology, parameters above the lower reference limits do not guarantee fertility, nor do values outside those limits necessarily imply male infertility or pathology $y^{26)}$. An abnormal semen analysis is suggestive of testicular germ cell damage, but azoospermia may also be secondary to ejaculatory dysfunction or hormone deficiencies in survivors at risk for those complications ${ }^{17)}$. When the ejaculate volume is less than 1.0 $\mathrm{mL}$, the physician should perform a postejaculatory urinalysis to rule out retrograde ejaculation ${ }^{27)}$.

\section{Endocrine evaluation}

The initial hormonal evaluation should consist of measurements of serum FSH, luteinizing hormone (LH), and testosterone levels as indicated clinically. Men with primary testicular failure typically show low circulating testosterone levels. When the hypothalamus-pituitary axis is intact, serum FSH and LH levels are elevated after puberty. However, if this axis is damaged by radiation, FSH and LH levels do not increase and remain within normal or low normal range.

Although serum inhibin B is known to be a marker of germ cell function, the levels of inhibin $B$ alone or inhibin B in combination with FSH do not reflect normal spermatogenesis in patients who have undergone cancer treatment in childhood ${ }^{28)}$. Therefore, the COG-LTFU guidelines do not recommend screening for inhibin B routinely ${ }^{17)}$.

\section{Testicular volume change}

Approximately $85 \%$ of the testicular mass consists of germinal tissue, so a reduced germinal cell mass is associated with reduced testicular size and a soft consistency ${ }^{29)}$. Azoospermic and severely oligoasthenozoospermic survivors of cancer had significantly smaller mean testicular volume and higher basal FSH levels than other survivors, but small testicles (sum of both testicular volume $\leq 20 \mathrm{~mL}$ ) and/or abnormally high basal FSH levels $(>10 \mathrm{mIU} / \mathrm{mL}$ ) were present in only half of the azoospermic survivors ${ }^{30)}$.

\section{Treatment of reduced fertility}

Male patients with hypogonadotropic hypogonadism usually require therapy with gonadotropin releasing hormone and human menopausal gonadotropin (or FSH) to induce spermatogenesis ${ }^{31)}$.

Cryopreservation of sperm before cancer therapy is a successful method for fertility preservation in postpubertal men ${ }^{32}$. Recent advances in sperm storage and in assisted reproductive technology, such as in vitro fertilization (IVF) and intracytoplasmic sperm injection (ICSI), can allow men to achieve successful pregnancies using cryopreserved spermatozoa ${ }^{33}$. Such cryopreserved gametes showed a 36.4\% successful pregnancy rate with intrauterine insemination and a $50.0 \%$ pregnancy rate with IVF and $\mathrm{ICSI}^{34)}$.

Fertility preservation for prepubertal male patients requires much more research because their spermarche has not yet started. One potential new fertility preservation technique is the cryopreservation of testicular tissue containing spermatogonial stem cells, but it is still experimental. Harvesting spermatogonial stem cells from preserved testicular tissue for in vitro maturation and testicular tissue grafting might be an option, but several hurdles remain ${ }^{16)}$.

Men with oligospermia can achieve fatherhood using IVF and ICSI because these techniques require only a minimal amount of spermatozoa for fertilization. In addition, new techniques for harvesting mature spermatozoa from testicular tissue, such as microsurgical epididymal sperm aspiration, testicular sperm extraction, and microscopic testicular sperm extraction (mTESE), have been applied to men with azoospermia for achieving fertilization using $\mathrm{ICS}^{35}$. When applying mTESE and ICSI to men with azoospermia after chemotherapy, the sperm retrieval rate was $37 \%$ and the fertilization rate was $57.1 \%{ }^{36)}$. 


\section{Conclusions}

With the development of new cancer treatments, more pediatric cancer patients can increase their life expectancy. Chemotherapy causes a variety of physical and psychological problems. With the increasing age of patients, reproductive problems including reduced fertility occur in male survivors of childhood cancer treated with alkylating agents, testicular radiation, or cranial radiation. At the end of chemotherapy, pubertal maturation, any testicular volume changes, and symptoms of androgen deficiency should be systematically monitored. If survivors reach 14 years of age or androgen deficiency is suspected, circulating testosterone and gonadotropin levels should be measured. If patients request fertility testing, spermatogenesis status can be evaluated either directly by semen analysis or indirectly by determination of the levels of testosterone and gonadotropins and by monitoring any changes in testicular volume. According to the patient's condition, semen cryopreservation, hormonal therapy, or assisted reproductive technologies such as IVF or ICSI should be provided. With these advances, we hope to develop better ways for preserving male fertility and thereby improve the health and quality of life of cancer survivors.

\section{Conflict of interest}

No potential conflict of interest relevant to this article was reported.

\section{References}

1. Ministry for Health, Welfare, and Family Affairs. Annual report of cancer incidence (2005) and survival (1993-2005) in Korea. Seoul: Ministry for Health, Welfare, and Family Affairs, 2008;98.

2. Han JW, Kim HS, Kim BS, Kwon SY, Shin YJ, Kim SH, et al. Increasing and worsening late effects in childhood cancer survivors during follow-up. J Korean Med Sci 2013;28:75562.

3. Jeruss JS, Woodruff TK. Preservation of fertility in patients with cancer. N Engl J Med 2009;360:902-11.

4. Darzy KH, Shalet SM. Hypopituitarism following radiotherapy revisited. Endocr Dev 2009;15:1-24.

5. Meistrich ML. Effects of chemotherapy and radiotherapy on spermatogenesis in humans. Fertil Steril 2013;100:11806.

6. Green DM, Kawashima T, Stovall M, Leisenring W, Sklar CA, Mertens AC, et al. Fertility of male survivors of childhood cancer: a report from the Childhood Cancer Survivor Study. J Clin Oncol 2010;28:332-9.

7. Meistrich ML, Wilson G, Mathur K, Fuller LM, Rodriguez MA, McLaughlin P, et al. Rapid recovery of spermatogenesis after mitoxantrone, vincristine, vinblastine, and prednisone chemotherapy for Hodgkin's disease. J Clin Oncol
1997; 15:3488-95.

8. da Cunha MF, Meistrich ML, Haq MM, Gordon LA, Wyrobek AJ. Temporary effects of AMSA (4'(9-acridinylamino) methanesulfon-m-anisidide) chemotherapy on spermatogenesis. Cancer 1982;49:2459-62.

9. Buchanan JD, Fairley KF, Barrie JU. Return of spermatogenesis after stopping cyclophosphamide therapy. Lancet 1975;2:156-7.

10. Kenney LB, Laufer MR, Grant FD, Grier H, Diller L. High risk of infertility and long term gonadal damage in males treated with high dose cyclophosphamide for sarcoma during childhood. Cancer 2001;91:613-21.

11. da Cunha MF, Meistrich ML, Fuller LM, Cundiff JH, Hagemeister FB, Velasquez WS, et al. Recovery of spermatogenesis after treatment for Hodgkin's disease: limiting dose of MOPP chemotherapy. J Clin Oncol 1984;2:571-7.

12. Jacob A, Barker H, Goodman A, Holmes J. Recovery of spermatogenesis following bone marrow transplantation. Bone Marrow Transplant 1998;22:277-9.

13. Hansen PV, Trykker H, Helkjoer PE, Andersen J. Testicular function in patients with testicular cancer treated with orchiectomy alone or orchiectomy plus cisplatin-based chemotherapy. J Natl Cancer Inst 1989;81:1246-50.

14. Sanders JE, Hawley J, Levy W, Gooley T, Buckner CD, Deeg HJ, et al. Pregnancies following high-dose cyclophosphamide with or without high-dose busulfan or total-body irradiation and bone marrow transplantation. Blood 1996;87:3045-52.

15. Marina S, Barcelo P. Permanent sterility after immunosuppressive therapy. Int J Androl 1979;2:6-13.

16. Wyns C, Curaba M, Vanabelle B, Van Langendonckt A, Donnez J. Options for fertility preservation in prepubertal boys. Hum Reprod Update 2010;16:312-28.

17. Kenney LB, Cohen LE, Shnorhavorian M, Metzger ML, Lockart B, Hijiya N, et al. Male reproductive health after childhood, adolescent, and young adult cancers: a report from the Children's Oncology Group. J Clin Oncol 2012;30:3408-16.

18. Rowley MJ, Leach DR, Warner GA, Heller CG. Effect of graded doses of ionizing radiation on the human testis. Radiat Res 1974;59:665-78.

19. Ogilvy-Stuart AL, Shalet SM. Effect of radiation on the human reproductive system. Environ Health Perspect 1993;101 Suppl 2:109-16.

20. Howell SJ, Shalet SM. Spermatogenesis after cancer treatment: damage and recovery. J Natl Cancer Inst Monogr 2005;(34):12-7.

21. Ash P. The influence of radiation on fertility in man. Br J Radiol 1980;53:271-8.

22. Meistrich ML. Male gonadal toxicity. Pediatr Blood Cancer 2009;53:261-6.

23. Shalet SM, Tsatsoulis A, Whitehead E, Read G. Vulnerability of the human Leydig cell to radiation damage is dependent upon age. J Endocrinol 1989;120:161-5.

24. World Health Organization. WHO laboratory manual for 
the examination and processing of human semen. 5th ed. Geneva:WHO Press, 2010.

25. Cooper TG, Noonan E, von Eckardstein S, Auger J, Baker HW, Behre HM, et al. World Health Organization reference values for human semen characteristics. Hum Reprod Update 2010;16:231-45.

26. Guzick DS, Overstreet JW, Factor-Litvak P, Brazil CK, Nakajima ST, Coutifaris C, et al. Sperm morphology, motility, and concentration in fertile and infertile men. $\mathrm{N}$ Engl J Med 2001;345:1388-93.

27. Male Infertility Best Practice Policy Committee of the American Urological Association; Practice Committee of the American Society for Reproductive Medicine. Report on optimal evaluation of the infertile male. Fertil Steril 2006;86(5 Suppl 1):S202-9.

28. Rendtorff R, Beyer M, Muller A, Dittrich R, Hohmann C, Keil T, et al. Low inhibin B levels alone are not a reliable marker of dysfunctional spermatogenesis in childhood cancer survivors. Andrologia 2012;44 Suppl 1:219-25.

29. Petak SM, Nankin HR, Spark RF, Swerdloff RS, Rodriguez-Rigau LJ; American Association of Clinical Endocrinologists. American Association of Clinical Endocrinologists Medical Guidelines for clinical practice for the evaluation and treatment of hypogonadism in adult male patients--2002 update. Endocr Pract 2002;8:440-56.
30. Lopez Andreu JA, Fernandez PJ, Ferris i Tortajada J, Navarro I, Rodriguez-Ineba A, Antonio P, et al. Persistent altered spermatogenesis in long-term childhood cancer survivors. Pediatr Hematol Oncol 2000;17:21-30.

31. Han TS, Bouloux PM. What is the optimal therapy for young males with hypogonadotropic hypogonadism? Clin Endocrinol (Oxf) 2010;72:731-7.

32. Ginsberg JP, Ogle SK, Tuchman LK, Carlson CA, Reilly MM, Hobbie WL, et al. Sperm banking for adolescent and young adult cancer patients: sperm quality, patient, and parent perspectives. Pediatr Blood Cancer 2008;50:594-8.

33. Feldschuh J, Brassel J, Durso N, Levine A. Successful sperm storage for 28 years. Fertil Steril 2005;84:1017.

34. Neal MS, Nagel K, Duckworth J, Bissessar H, Fischer MA, Portwine C, et al. Effectiveness of sperm banking in adolescents and young adults with cancer: a regional experience. Cancer 2007;110:1125-9.

35. Schwarzer JU, Fiedler K, v Hertwig I, Krusmann G, Wurfel $\mathrm{W}$, Schleyer M, et al. Sperm retrieval procedures and intracytoplasmatic spermatozoa injection with epididymal and testicular sperms. Urol Int 2003;70:119-23.

36. Hsiao W, Stahl PJ, Osterberg EC, Nejat E, Palermo GD, Rosenwaks Z, et al. Successful treatment of postchemotherapy azoospermia with microsurgical testicular sperm extraction: the Weill Cornell experience. J Clin Oncol 2011;29:1607-11. 